American Journal of Pharmaceutical Education 2017; 81 (3) Article 42.

\title{
COMMENTARY
}

\section{Recruiting the Right Students}

\author{
Claire Anderson, $\mathrm{PhD}, \mathrm{BPharm}{ }^{\mathrm{a}, \mathrm{b}}$ \\ ${ }^{a}$ University of Nottingham, Nottingham, United Kingdom \\ ${ }^{\mathrm{b}}$ Associate Editor, American Journal of Pharmaceutical Education \\ Submitted February 13, 2017; accepted February 19, 2017; published April 2017.
}

What do we want pharmacists in 2030 and beyond to be like? What competencies will they require? What jobs will they be doing? To answer these questions, we need to ask ourselves what type of students are we recruiting? The pharmacy students we recruit today will be the pharmacists in the next 40 to 50 years.

The FIP Nanjing Declaration states that "pharmacists and pharmaceutical scientists [should] accept responsibility for the development and sustainability of an adaptable and capable global workforce working in partnership for better health care through transformative and continuous education." "A coordinated approach between professional leaders, educational bodies and governmental departments is needed to link pharmacy workforce planning and education (including an adequate and genderbalanced pipeline of qualified trainees from rural and remote areas), and to encourage interprofessional education and collaborative practice. ${ }^{2}$ The social mission of health education institutions represents an opportunity to nurture in health professionals the public service ethics, professional values and social accountability attitudes requisite to deliver respectful care that responds to local needs and population expectations. ${ }^{2}$

It is important to take into account a country's local needs; ${ }^{1,2}$ what works for a certain country or region, may not work for another country or region. For example, one country may require pharmacists who are clinically skilled and ready to prescribe medicines, while another country may require at least a proportion of pharmacists who can work in the pharmaceutical industry or perform scientific research, and yet another country may require pharmacists to work in public health systems in rural areas. Greater alignment is needed between pharmacy schools and health systems. Institutions should consider using targeted admissions policies to increase the socioeconomic, ethnic, and geographical diversity of students. Institutions need to overcome gender discrimination in

Corresponding Author: Claire Anderson, School of Pharmacy, University of Nottingham, Nottingham, United Kingdom NG72RD. Tel: +44-115-951-5389. E-mail: Claire. Anderson@Nottingham.ac.uk their admissions process. The shortage of qualified pharmacists and other health workers in remote and rural areas impedes access to health services for a significant percentage of the population, slows progress toward attaining the United Nation's sustainable development goals, and challenges the aspirations of achieving health for all.

Selection strategies, summer schools and pre-course foundation programs that ensure equality and diversity in which people from underserved communities are encouraged to pursue pharmacy careers can effectively achieve a fair and equitable representation of students from underserved communities. Such strategies in medicine have contributed to diverse student bodies with strong intentions to work with underserved populations. Using targeted admission policies to recruit students with a rural background in education programs for various health disciplines has been shown to increase the likelihood of graduates choosing to practice in rural areas. ${ }^{3}$ It may also be important to locate campuses, placements, rotations, and residency or foundation programs outside of a country's capital and other major cities as graduates of these schools and programs are more likely to work in rural areas.

We all would like our students to be academically excellent, well-rounded, good communicators, and able to work collaboratively in teams. With the growing number of people with long-term, chronic health conditions and multimorbidity, the increasing complexity of medicines, and the march to automation, the roles of pharmacists have changed considerably. Nowadays, pharmacists hold longer, more complex consultations often with people who are frail and vulnerable and will need to have qualities such as empathy and caring. Scientific knowledge, and clinical and technical expertise alone, are insufficient to deliver best patient care. Pharmacists also need to be able to intervene effectively on social determinants of health and have expertise in public health.

Everyone whom we interview will have their own values based on their personal beliefs in a social, political, religious or cultural sense. Shaw and colleagues stated that in moving to more clinical and public health roles, pharmacists will require enhanced skills in areas such as consultation, diagnosis, physical assessment, clinical 


\section{American Journal of Pharmaceutical Education 2017; 81 (3) Article 42.}

decision-making, prescribing, communication, and moral reasoning. ${ }^{4}$ Additionally, pharmacy students need to be forward thinking and socially confident by developing leadership and management entrepreneurial skills and be able to work collaboratively. How do we recruit students with such potential? If we rely only on high school GPAs, pre-pharmacy grades or pharmacy specific admission tests, we are missing a key factor. We may get good students who'll succeed in exams but will they have the caring attributes, values, leadership, collaborative and entrepreneurial skills that the pharmacy profession must enhance and develop?

Consider the interviews that you have conducted in the past. How long did it take you to decide about the person you were interviewing? People tend to make judgments quickly, which is why much of industry uses multiple interviews with multiple interviewers before offering a candidate the position. This is the basis of multiple mini interviews (MMIs), an admissions instrument designed to replace a personal interview in health care student selection. Its effectiveness has been evaluated in medical student recruitment processes. ${ }^{5,6}$ They are increasingly being used by pharmacy programs as part of the recruitment process. When candidates move around several stations meeting different interviewers, multiple first impressions are created which can then be combined to produce a clearer picture of the candidate. Also, if a candidate performs poorly at one station, he or she has a chance to recover on the remaining stations. MMIs may be better than traditional interviews because the multirater assessment offers good reliability. The scenarios are not intended to assess clinical knowledge; rather, they focus on random subject areas designed to assess predefined personal qualities. This makes it more difficult for candidates to anticipate questions and prepare answers, and benefit from any prior "coaching." The scenarios are designed so there are no "correct" answers. Respondents are required to offer possible solutions or responses to the questions demonstrating an appreciation of the complexity of the issues. In clinical practice, often, there is no "right or wrong" but an inquiring mind is needed to be able to respond creatively while appreciating situations from a range of perspectives. At the University of Nottingham, we have a number of MMI stations where we interview candidates on their communication skills, ethics, values, knowledge and application of science into practice, motivation for pharmacy and a group exercise where we look for teamwork skills.

I believe using MMIs helps us recruit students who will be equipped to practice pharmacy for the next 40 50 years. We need to reflect on our selection procedures and make them the best that we can. As Shaw and colleagues said, "Because of contextual diversity, a bestpractice model for pharmacy student selection is unlikely. However, all schools should reflect on their selection policies and procedures in light of the changes in practice and the needs of future practitioners." 4

\section{REFERENCES}

1. World Health Organization. Global strategy on human resources for health: workforce 2030. WHO, Geneva 2016.

2. Anderson C, Bates I, Beck D, et al. The WHO UNESCO FIP Pharmacy Education Taskforce: enabling concerted and collective global action. Am J Pharm Educ. 2008;72(6):Article 127.

3 . WHO Increasing access to health workers in remote and rural areas through improved retention. Global policy recommendations. WHO, Geneva, 2010.

4. Shaw J, Kennedy J, Jensen M, Sheridan J. An international perspective on pharmacy student selection policies and processes. $\mathrm{Am}$ J Pharm Educ. 2015;79(8):Article 115.

5. Eva K, Rosenfeld J, Reiter H, Norman G. An admissions OSCE: the multiple mini-interview. Med Educ. 2004;38(3):314-326.

6. Roberts C, Clark T, Burgess A, Frommer M, Grant M, Mossman $\mathrm{K}$. The validity of a behavioural multiple mini interview within an assessment centre for selection into speciality training. BMC Med Educ. 2014;14:169. 